\title{
DIAGRAMMING PRIOR KNOWLEDGE IN THE CLASSROOM
}

\author{
Arthur Thomas Conroy III ${ }^{1}$
}

\begin{abstract}
Engaging the student's prior knowledge is considered by educational researchers to be an important part of constructing a strong foundation for new learning. Diagrams are one technique used in the classroom. Jill Larkin and Herbert Simon described the computational advantages of diagrams over text when used to communicate information in their 1987 article entitled "Why a Diagram is (Sometimes) Worth Ten Thousand Words." This presentation describes a novel abstract diagramming technique designed to be facilitated in the classroom. Using paper and crayons, the participants create three diagrams that represent the externalization of their own prior knowledge of concepts in a domain of study. The presentation illustrates how differences in prior knowledge can be visualized using diagrams with greater speed in less time than the traditional use of textbased descriptions. The student diagrams were shown to contain a hidden conceptual topology, one that is described by Egenhofer in his 1991 article entitled "Reasoning About Binary Topological Relations." This topology is recommended as a framework for structuring and facilitating student collaboration and sharing of prior knowledge and new learning.
\end{abstract}

Discovery of experiential backgrounds with students is often conducted with the use of a common spoken language that is shared by the students and instructor during classroom conversations. Natural spoken languages are rich in content and context. These modalities combine to enable students and instructors to quickly send and receive messages, assign meaning to the interchanges, and generate inferences from the experience. A conversation rarely evokes the need for a lengthy inquiry regarding the prior knowledge of either party. The challenge of exploring prior knowledge using a shared language such as English, limits the depth to which individuals may share their personal worldviews. The inspiration for this article was based on the experience of teaching a three-day technical course in six countries over a period of several weeks. Engineers and managers from the United States, Mexico, Great Britain, Columbia, Brazil, and Sweden were provided a simple rectangle as the over-arching mental model to be used in representing the complexity experienced when managing data warehouses. The use of geometric shapes as an ad hoc grammar to communicate complex topics led to research that formalized the technique in the form of a visual language referred to as Draw Aloud.

To better understand how a visual language could be used to communicate the complex epistemologies found in classroom setting, research into the nature of visual language was conducted in the form of a case study at two universities. The students were observed creating diagrams of prior knowledge using a novel abstract diagram elicitation technique. The technique was facilitated in four different classroom settings. The

\footnotetext{
${ }^{1}$ Arthur Thomas Conroy III, PhD: Adjunct Professor, George Mason University, Fairfax, VA, United States. Email: conroyat@vt.edu
} 
research described how the diagramming technique was made operational, how the student-generated diagrams revealed a hidden topology of shapes, how the shapes supported a framework for sharing and collaboration, and how the instructors responded to their experience of sponsoring the diagram elicitation technique. The research was based on the use of node-link diagrams and pattern matching skills (Larkin, McDermott, Simon, \& Simon, 1980; Larkin \& Simon, 1987).

The research was also informed by works originating in the fields of systems engineering and data modeling. The development of computer system architecture is based on the use of entity-relationship (E-R) diagrams to model systems in large organizations (Chen, 1975). These types of diagrams function as conceptual models of how organizations operate and how they manage their resources. The concept of using diagrams as the focal point of the case study was reinforced by experiences originating from participation in graduate courses in adult learning and human development (Boucouvalas, 2009; Morris, 2009; Renard, 2009). The course subjects included adult learning theory and practice, small group theory and practice, and consulting in human systems theory and practice. The discourse during the semester confirmed that the prior knowledge of the students' conceptualization about adult learning theories varied widely. The survey of existing research related to the challenges of engaging prior knowledge led to the discovery of a gap in the literature concerning the use of diagram elicitation techniques in adult learning settings.

\section{The Original Prototype}

The human communications that transpire in the classroom are in the abstract, cognitive schemas originating from deep within the unconscious mind. The use of abstract shapes in the form of a visual language serves to make this communication, normally hidden from view, visible in a very sensory way. The original prototype of the visual language used an experimental technique that required university graduate students to create three diagrams using butcher block paper, glue sticks, and cut-outs of geometric shapes (Klunk, 2009). Three questions were posed to the students as a way of eliciting a response aimed at making diagrams of prior knowledge externally visible. The questions were based on findings by a National Research Council project that summarized key recommendations for teachers when engaging students in new learning (Bransford, 2000). The elicitation questions were designed to elicit the student's general prior knowledge of conceptualizations about how the world worked. The questions appear below.

1) How does the world work?

2) How do you store that information in memory?

3) How do you monitor your own learning when things change in the real world?

Each student was instructed to use the materials to create an answer to each of the three questions, all in the form of diagrams, made from the geometric shape pieces, and then instructed to glue the shapes to the butcher block paper. At the conclusion of the diagram generation phase of the exercise, the students provided verbal explanations of what their diagrams were meant to communicate. The outcomes of the experiment in the university 
setting and the six international workshop settings were the same. Regardless of the domain-specific nature of the context, the resulting diagrams were different for every person and for each question. The visual language made it easy to externalize and illustrate to participants how very different their worldviews appeared when represented as abstract diagrams.

\section{The Nature of Conceptual Coherence in the Classroom}

The observations and conceptualizations about coherence as it is represented in abstract diagrams is situated within the disciplines of adult learning (Knowles, Holton, \& Swanson, 2005) and human development (Deacon, 1998; Staats, 2012). The research indicates that the diagrams are grounded in the philosophy of constructivism as the conceptual framework (Fosnot, 1996). Early discourse in philosophy informed human inquiry into learning and development during the time of Plato and Aristotle. More recently, the modern origins of constructivism evolved through the works of Dewey (1916), Piaget (1954), and Vygotsky (1978). The constructivist research by Ausubel (1960) when developing advanced organizers provided one of the first techniques for externalizing and illustrating in a material way, how physical artifacts can be used to represent prior knowledge in the classroom. The evolution of constructivist theories in recent years has further refined the nature of communication across borders from the perspective that the interchange is the result of the cognitive processes of the parties collaborating in a conceptual space (Fiorini, Gardenfors, \& Abel, 2014; Gardenfors, 2014; Gardenfors \& Zenker, 2013; Warglien \& Gardenfors, 2013). The abstract diagramming technique made visible the incoherence of unconsciousness prior knowledge when framed within a conceptual space - the abstract diagram.

\section{The Visible Nature of Incoherence}

The visible nature of prior knowledge incoherence when communicating new material in the classroom is rooted in the interdisciplinary nature of learning sciences research (Jacobson \& Wilensky, 2006). There is a significant body of literature on diagrams, prior knowledge, and the assessment of prior knowledge. On closer inspection, the range of topics in the field of diagram research spans many disciplines and definitions of what constitutes a diagram. Purchase (2014, p. 59) offers a definition of a diagram as "taken to mean a composite set of marks (visual elements) on a two-dimensional plane that, when taken together, represent a concept or object in the mind of the viewer." The Larkin and Simon (1987, p.68) definition of a diagram is that of a "data structure in which information is indexed in a two-dimensional location". To minimize the incoherence when comparing renderings in a visual language, this definition was chosen as best representative of how abstract diagrams containing geometric shapes use location to describe cultural and international border features. Researchers further classify these features into sub-classes described as declarative, procedural, and conceptual prior knowledge (Duffy \& Jonassen, 1993; Jonassen, Beissner, \& Yacci, 1993). It is conceptual knowledge that is considered to be the foundation of what causes incoherence when prior knowledge features lack a shared understanding or structure (Dochy, Segers, \& Buehl, 1999; Eppler, 2006; Jonassen, 2004; Sowa, 1984; Vosniadou, 2008). The wide variation in abstract diagrams is visual evidence of this incoherence. 


\section{Mediating Incoherence in the Classroom}

The emergence of research related to the use of abstract diagrams as a technique for creating shared understanding and exploring differences in prior knowledge is still early in the discovery phase. This article is just one example and is designed to create a bridge to the emerging research in other disciplines. Diagrams are implemented as a technique to visualize concepts (Burton, Stapleton, Howse, \& Chapman, 2014) in formal logic. Diagrams are used to study meaning in mathematics (Dimmel \& Herbst, 2015). Research explores the use of diagrams in professional practice (Giardino, 2013). Political scientists use diagrams in qualitative studies (Mahoney \& Vanderpoel, 2015). Diagrams are used in design studies and the cognitive sciences (Nickerson et al., 2013; Tversky, 2011; Tversky \& Kessell, 2014; Tversky \& Suwa, 2009). Diagrams are used in research to understand how exceptional children learn (Poch, van Garderen, \& Scheuermann, 2015; van Garderen \& Scheuermann, 2015; van Garderen, Scheuermann, \& Jackson, 2013). Diagrams are used in the health sciences field to collect data in qualitative research settings (Burchett, Umoquit, \& Dobrow, 2011; Umoquit, Tso, Burchett, \& Dobrow, 2011; Umoquit, Tso, Vargas-Atkins, O'Brien, \& Wheeldon 2013). The use of simple abstract diagrams as a tool for navigating prior knowledge is in reality, an ancient form of human communications that dates back thousands of years. The Draw Aloud Protocol formalizes the use of abstract diagrams as a visual language that makes eliciting prior knowledge in the classroom transparent and visually accessible.

\section{Diagramming in the Wild}

The feature of a useful human language is that it is grounded in a general theory that can be implemented in the wild. The use of abstract geometric shapes as a set of rules embedded in a visual grammar describes such a language. How can abstract diagrams constrained by domain-general, geometric shapes be made operational in a classroom setting? The diagram prototype technique created for the adult learning class (Klunk, 2009) used large sheets of white poster paper, geometric shape foam pieces, and glue sticks. This led to the refinement and the need to explore "diagramming in the wild". Since blank sheets of paper and crayons can be found in many settings, these materials serve as a blank canvas. Three questions are used as prompts to elicit the visual responses. The question format is based on three summary findings made in the National Research Council report about the nature of how humans learn (Bransford, 2000). The report included three observations that related to epistemology, long-term memory, and meta-cognition. The format for the three questions is provided below.

How do you think works?

How do you store information about in long term memory?

How do you monitor your own learning about ?

Set against the background of Cultivating Creative and Reflective Learners, the questions can be reframed within the context of students and teachers creating a shared understanding related to Cultivating Creative and Reflective Learners. The questions in this context would be rewritten as they appear below. 
How do you think Cultivating Creative and Reflective Learners works?

How do you store information about Cultivating Creative and Reflective Learners in long term memory?

How do you monitor your own learning about Cultivating Creative and Reflective Learners?

The value of any instrument created to facilitate communications between human beings is the efficacy with which the tool faithfully communicates the message with a minimum of noise (Shannon, 1948). Such a tool is especially useful if it has the ability to predict in advance what the nature of the outcome will be as a result of the discourse. Asking participants to draw abstract diagrams in response to questions about Cultivating Creative and Reflective Learners resulted in different diagrams being generated for each question and from each participant.

\section{Eliciting Diagrams}

The facilitation and eliciting abstract diagrams is the basis for helping teachers and students navigate their differences related to conceptualizations about prior knowledge in specific subject domains. The steps for facilitating such an outcome are provided below.

1. Explain to the participants that they will be participating in an exercise that asks them to create diagrams using geometric shapes in response to three questions.

2. Explain to the participants that the objective of the diagram exercise is to enable them to share their individual interpretations with others of how they conceptualize their prior knowledge and experiences about the concepts of Cultivating Creative and Reflective Learners

3. Explain to the participants that they will have five minutes to complete each diagram in response to each of three questions.

4. The facilitator has the option of asking the participants to explain their diagrams to fellow participants upon completion of the exercise.

5. Hand out the materials to the participants. Each person is provided with three sheets of blank paper and several colored crayons they select from a box of crayons.

6. Once the participants have received the materials, ask them to think of a random eight digit number. Ask them to write the number in the upper right hand corner of the three sheets of paper. Explain to them that this random number is used to reassemble the sheets of paper in the event that the diagrams become separated. Repeat for the participants' benefit how the number should not contain any personal identifying marks embedded in the string such as social security numbers, birth dates, or similar identity numbers.

7. The next step in the process is to explain to the participants that the diagrams can only contain triangles, squares, and circles. The diagrams should not contain any other markings. Letters, numbers, special symbols, lines, arrows, points, or another marks are not allowed as part of the diagram constructions. Explain to the participants that they are free to create the diagrams using the geometric shapes in any configuration, composition, quantity, order, or layout. 
8. Before proceeding with the timed portion of the facilitation ask the participants if they have any questions.

9. State the questions one at a time. Allocate five minutes for each question. Remind the participants to fill in the blank with the question topic - such as Cultivating Creative and Reflective Learners. Announce to the participants that they can begin to answer the first question. At the four minute mark, announce to the participants that they have one minute left. Ask the participants to complete the diagram for the first question at the five minute mark. Ask the participants to turn the diagram face down. Repeat the timed portion as described above for the two remaining questions.

10. At the completion of the timed diagramming period, ask the participants to pass the diagrams to the front of the room. This completes the steps involved in conducting the facilitation exercise. As mentioned above, there is an optional step of asking each participant to explain their diagrams to the group before the diagrams are collected.

\section{Framing the Differences of Prior Knowledge}

One of the key insights from the research was the existence of a pattern of relations that are known as the eight binary topological relations (Egenhofer, 1991). These relations are recognized internationally as the standard for describing geometric topologies (Kresse \& Danko, 2012). The diagrams have embedded in them hidden patterns of binary relations that are not self-evident to the casual observer, yet have significant meaning to an expert when analyzing the diagrams. The relationships between the shapes in the diagrams create the opportunity to explore how each participant defines and positions key terms in the conceptual space - in this article, the scenario is that of participants creating diagrams related to shapes representing prior knowledge of Cultivating Creative and Reflective Learners. The possible binary relations that can exist between two conceptualizations and features related to Cultivating Creative and Reflective Learners are described as being disjoint, meeting at a shared edge, being equal to one another, one feature being contained inside another, one feature be covered by another, one feature containing another but not being part of the container, a feature that is covered by another, and two features that overlap. These features of a conceptual topology provide a broad landscape for visualizing how one can navigate Cultivating Creative and Reflective Learners.

The use of abstract diagrams as defined in this article is not a technique that appears in the education literature. This article proposes the Draw Aloud abstract diagram method as one approach for use in classroom practice and as a technique for designing and constructing conceptual models for navigating the various levels and capabilities of understanding related to Cultivating Creative and Reflective Learners. In light of the breadth and depth to which diagrams permeate educational settings, a visual language may empower those seeking to teach with greater impact to explore deeper levels of similarities and differences using a common visual language such as Draw Aloud.

Speculating on what the abstract shapes mean is not the objective of the technique as an outcome. The abstract diagrams are intended to represent a conceptualization of the participant's prior knowledge in a domain specific subject area. The analysis of the diagrams can be performed in a way in which it may reveal a hidden pattern of topological features related to prior knowledge incoherence in individuals, teams, and 
groups. This approach has the potential to illustrate that shapes by their visual features may be used to categorize these similarities and differences in incoherence.

\section{Why a Diagram is (Sometimes) Worth 10,000 Words}

Jill Larkin and Herbert Simon aptly coined the phase above as the title for their 1987 article that discusses the power of diagrams to accelerate the cognitive processes of search, pattern matching and inference generation. Just a handful of diagrams can provide a powerful visual representation of how different conceptual knowledge is between individuals and hidden from view in the unconscious mind. The diagrams that follow illustrate how visible differences can be when captured in external representations.

The diagrams in Figure 1 illustrate the differences in student conceptualizations of prior knowledge related to college teaching.

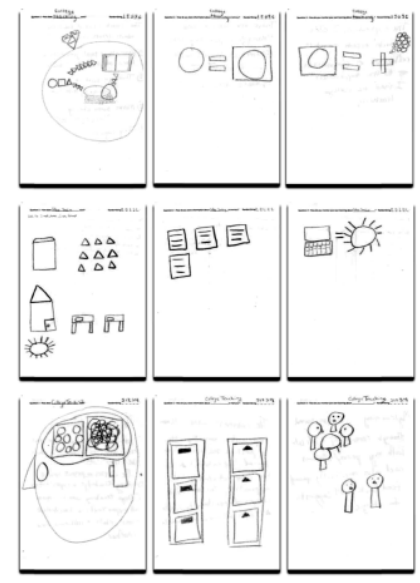

Figure 1. Abstract Diagrams of College Teaching Concepts

The diagrams in Figure 2 illustrate the differences in student conceptualizations of prior knowledge related to project management.

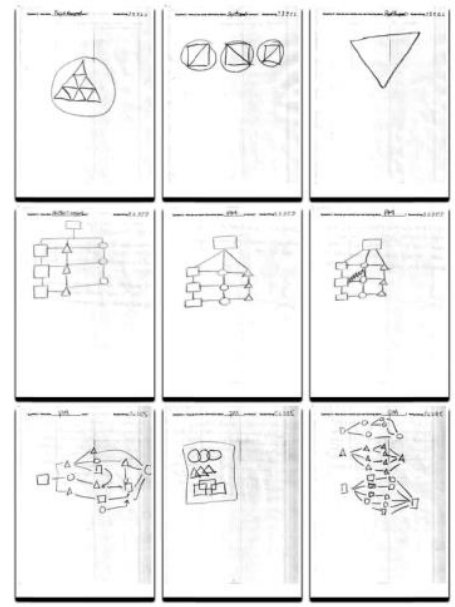

Figure 2. Abstract Diagrams of Project Management Concepts 
It was highly probable that diagrams created to represent conceptualizations of prior knowledge about Cultivating Creative and Reflective Learners would vary from person to person much like those above. They did vary as anticipated. The power of a visual language is the universal nature with which the differences can be perceived by both the sender and the receiver. There is very little semantic noise to obscure the clear differences and similarities. A visual language such as Draw Aloud serves as a simple canvas upon which a far deeper understanding can be developed when exploring and sharing prior knowledge in the classroom setting.

\section{References}

Ausubel, D. (1960). The use of advance organizers in the learning and retention of meaningful verbal material. Journal of Educational Psychology, 51(5), 267-272. doi:10.1037/h0046669

Boucouvalas, M. (2009). ALHR 5514 Adult Learning[Course syllabus]. Falls Church, VA: Department of Human Development, Adult Learning and Human Resource Development. Virginia Tech/National Capital Region.

Bransford, J. (2000). How people learn : Brain, mind, experience, and school. Washington, DC: National Academy Press.

Burchett, H., Umoquit, M., \& Dobrow, M. (2011). How do we know when research from one setting can be useful in another? A review of external validity, applicability and transferability frameworks. Journal of Health Services Research \& Policy, 16(4), 238-244. doi:10.1258/jhsrp.2011.010124

Burton, J., Stapleton, G., Howse, J., \& Chapman, P. (2014). Visualizing concepts with euler diagrams. In T. Dwyer, H. Purchase, \& A. Delaney (Eds.), Diagrammatic representation and inference (pp. 54-56). Berlin, Germany: Springer.

Chen, P. (1975). The entity-relationship model: Toward a unified view of data. SIGIR Forum, 10(3), 9-9. doi:10.1145/1095277.1095279

Deacon, T. (1998). The symbolic species : The co-evolution of language and the brain. New York, NY: W.W. Norton.

Dewey, J. (1916). Democracy and education : An introduction to the philosophy of education. New York, NY: Macmillan.

Dimmel, J., \& Herbst, P. (2015). The semiotic structure of geometry diagrams: How textbook diagrams convey meaning. Journal for Research in Mathematics Education, 46(2), 147-195. doi:10.5951/jresematheduc.46.2.0147

Dochy, F., Segers, M., \& Buehl, M. (1999). The relation between assessment practices and outcomes of studies: The case of research on prior knowledge. Review of Educational Research, 69(2), 145-186. doi:10.3102/00346543069002145

Duffy, T., \& Jonassen, D. (1993). Constructivism and the technology of instruction : A conversation. Hillsdale, NJ: Lawrence Erlbaum Associates. 
Egenhofer, M. (1991). Reasoning about binary topological relations. Lecture notes in computer science, (pp. 144-160).Berlin, Germany: Springer

Egenhofer, M. (1994). Deriving the composition of binary topological relations. Journal of Visual Languages \& Computing, 5(2), 133-149. doi:10.1006/jvlc.1994.1007

Egenhofer, M., \& Golledge, R. (1998). Spatial and temporal reasoning in geographic information systems. New York, NY: Oxford University Press.

Eppler, M. (2006). A comparison between concept maps, mind maps, conceptual diagrams, and visual metaphors as complementary tools for knowledge construction and sharing. Information Visualization, 5(3), 202-210. doi:10.1057/palgrave.ivs.9500131

Fiorini, S., Gardenfors, P., \& Abel, M. (2014). Representing part-whole relations in conceptual spaces. Cognitive Processing, 15(2), 127-142. doi:10.1007/s10339013-0585-x

Gardenfors, P. (2014). The geometry of meaning semantics based on conceptual spaces. Cambridge, MA: MIT Press.

Gardenfors, P., \& Zenker, F. (2013). Theory change as dimensional change: Conceptual spaces applied to the dynamics of empirical theories. Synthese, 190(6), 10391058. doi:10.1007/s11229-011-0060-0

Giardino, V. (2013). A practice-based approach to diagrams. In A. Moktefi \& S.-J. Shin (Eds.), Visual reasoning with diagrams (pp. 135-151). Berlin, Germany: Springer.

Jacobson, M., \& Wilensky, U. (2006). Complex systems in education: Scientific and educational importance and implications for the learning ciences. The Journal of the Learning Sciences, 15(1), 11-34.

Jonassen, D. (2004). Learning to solve problems : An instructional design guide. San Francisco, CA: Pfeiffer.

Jonassen, D., Beissner, K., \& Yacci, M. (1993). Structural knowledge : Techniques for representing, conveying, and acquiring structural knowledge. Hillsdale, NJ: Lawrence Erlbaum Associates.

Klunk, C. (2009). ALHR 5584 Facilitating Adult Learning[Course syllabus]. Falls Church, VA: Department of Human Development, Adult Learning and Human Resource Development. Virginia Tech/National Capital Region.

Knowles, M., Holton, E., \& Swanson, R. (2005). The adult learner : The definitive classic in adult education and human resource development. Amsterdam, MA: Elsevier.

Kresse, W., \& Danko, D. (2012). Springer handbook of geographic information (Vol. 1). New York, NY: Springer. 
Larkin, J., McDermott, J., Simon, D. P., \& Simon, H. A. (1980). Expert and novice performance in solving physics problems. Science, 208(4450), 1335-1342. doi:10.1126/science.208.4450.1335

Larkin, J., \& Simon, H. A. (1987). Why a diagram is (sometimes) worth ten thousand words. Cognitive Science, 11(1), 65-100. doi:10.1016/S0364-0213(87)80026-5

Mahoney, J., \& Vanderpoel, R. (2015). Set diagrams and qualitative research. Comparative Political Studies, 48(1), 65-100. doi:10.1177/0010414013519410

Morris, L. (2009). ALHR 5544 Small Groups in Adult Learning[Course syllabus]. Falls Church, VA: Department of Human Development, Adult Learning and Human Resource Development. Virginia Tech/National Capital Region.

Nickerson, J., Corter, J., Tversky, B., Rho, Y., Zahner, D., \& Yu, L. (2013). Cognitive tools shape thought: Diagrams in design. Cognitive Processing, 14(3), 255-272. doi:10.1007/s10339-013-0547-3

Piaget, J. (1954). The construction of reality in the child. New York, NY: Basic Books.

Poch, A., van Garderen, D., \& Scheuermann, A. (2015). Students' understanding of diagrams for solving word problems: A framework for assessing diagram proficiency. Teaching exceptional children, 47(3), 153-162.

Purchase, H. (2014). Twelve years of diagrams research. Journal of Visual Languages \& Computing, 25(2), 57-75. doi:10.1016/j.jvlc.2013.11.004

Renard, P. (2009). ALHR 6814 Consulting With Human Systems[Course syllabus]. Falls Church, VA: Department of Human Development, Adult Learning and Human Resource Development. Virginia Tech/National Capital Region.

Shannon, C. E. (1948, July \& October). A mathematical theory of communication. Bell System Technical Journal, 27, 379-423 and 623-656.

Sowa, J. (1984). Conceptual structures : Information processing in mind and machine. Reading, MA: Addison-Wesley.

Staats, A. (2012). The marvelous learning animal : What makes human nature unique. Amherst, NY: Prometheus Books.

Tversky, B. (2011). Visualizing thought. Topics in Cognitive Science, 3(3), 499-535. doi:10.1111/j.1756-8765.2010.01113.x

Tversky, B., \& Kessell, A. (2014). Thinking in action. Pragmatics \& Cognition, 22(2), 206-223.

Tversky, B., \& Suwa, M. (2009). Thinking with sketches. Tools for innovation (pp. 7584). Oxford, England: Oxford University Press.

Umoquit, M., Tso, P., Burchett, H., \& Dobrow, M. (2011). A multidisciplinary systematic review of the use of diagrams as a means of collecting data from 
research subjects: Application, benefits and recommendations. BMC Medical Research Methodology, 11(1), 11.

Umoquit, M., Tso, P., Vargas-Atkins, T., O'Brien, M., \& Wheeldon , J. (2013). Diagrammatic elicitation: Defining the use of diagrams in data collection. Qualitative Report, 18(30), 1.

van Garderen, D., \& Scheuermann, A. (2015). Diagramming word problems: A strategic approach for instruction. Intervention in School and Clinic, 50(5), 282-290. doi: $10.1177 / 1053451214560889$

van Garderen, D., Scheuermann, A., \& Jackson, C. (2013). Examining how students with diverse abilities use diagrams to solve mathematics word problems. Learning Disability Quarterly, 36(3), 145-160. doi:10.1177/0731948712438558

Vosniadou, S. (2008). International handbook of research on conceptual change. New York, NY: Routledge.

Vygotsky, L. (1978). Mind in society: The development of higher psychological processes. Cambridge, MA: Harvard University Press. 